\title{
The effects of the Wnt/ $\beta$-catenin signaling pathway on apoptosis in HeLa cells induced by carbon ion irradiation
}

\author{
JING SI $^{1-3^{*}}$, JINHUA ZHANG $^{1-3^{*}}$, LU GAN $^{1-3}$, MENGHUAN GUO $^{4}$, YI XIE $^{1-3}$, CUIXIA DI $^{1-3}$, \\ CHAO SUN ${ }^{1-3}$, FANG WANG ${ }^{1-3}$, JUNFANG YAN ${ }^{1-3}$ and HONG ZHANG ${ }^{1-3}$ \\ ${ }^{1}$ Institute of Modern Physics, Chinese Academy of Sciences; ${ }^{2}$ Key Laboratory of Heavy Ion Radiation Biology \\ and Medicine of The Chinese Academy of Sciences, Lanzhou, Gansu $730000 ;{ }^{3}$ College of Life Sciences, \\ University of The Chinese Academy of Sciences, Beijing 101400; ${ }^{4}$ School of Pharmacy, \\ Lanzhou University, Lanzhou, Gansu 730000, P.R. China
}

Received January 1, 2020; Accepted March 24, 2020

DOI: $10.3892 / o r .2020 .7581$

\begin{abstract}
The molecular mechanisms underlying the biological effects of carbon ions are unclear. The aim of this study was to explore the $\mathrm{Wnt} / \beta$-catenin pathway in regulating carbon ion $\left({ }^{12} \mathrm{C}^{6+}\right)$ radiation-induced cellular toxicity. HLY78 is a Wnt-specific small molecular modulator, whose effects on ${ }^{12} \mathrm{C}^{6+}$ radiation-induced damage are mostly unknown. HLY78, in combination with ${ }^{12} \mathrm{C}^{6+}$ radiation was investigated on HeLa cell viability, cell cycle progression, DNA damage, and the expression of apoptotic and Wnt-related proteins. ${ }^{12} \mathrm{C}^{6+}$ radiation suppressed cell viability in a time-dependent manner, whereas the addition of HLY78 to cells significantly reduced this stress. Moreover, after irradiation with ${ }^{12} \mathrm{C}^{6+}$, HeLa cells exhibited increased cell apoptosis, G2/M phase arrest, and a number of $\gamma$-H2AX foci. However, Wnt signaling activation alleviated these effects. Furthermore, when compared with the radiation alone group, supplementation with HLY78 markedly increased the expression of anti-apoptotic and Wnt-related proteins, and significantly decreased the expression of apoptotic proteins. The present results indicated that activation of the $\mathrm{Wnt} / \beta$-catenin signaling pathway by HLY78 reduced ${ }^{12} \mathrm{C}^{6+}$ radiation-induced HeLa cell dysfunction, suggesting that the Wnt/ $\beta$-catenin signaling pathway plays an important role in regulating ${ }^{12} \mathrm{C}^{6+}$ radiation-induced cellular toxicity in HeLa cells.
\end{abstract}

\section{Introduction}

Worldwide each year, approximately 500,000 women are diagnosed with cervical cancer, and more than 300,000 deaths

Correspondence to: Professor Hong Zhang, Institute of Modern Physics, Chinese Academy of Sciences, 8 Tianshui Middle Road, Chengguan, Lanzhou, Gansu 730000, P.R. China

E-mail: zhangh@impcas.ac.cn

\section{${ }^{*}$ Contributed equally}

Key words: ${ }^{12} \mathrm{C}^{6+}$ irradiation, cervical cancer, Wnt/ $\beta$-catenin pathway, HLY78, radio-sensitivity are recorded from this malignancy (1). In most cases, persistent infection with high-risk human papillomavirus (HPV) is reported to be the cause of the cervical carcinoma (2). Approximately $90 \%$ of new cases and deaths from cervical cancer occur in low- and middle-income countries, where mortality rates are 18 times higher than developed countries $(1,3)$. Traditional treatments for cervical cancer involve radical hysterectomy, chemotherapy, radiotherapy, or a combination of both. Currently, nearly $70 \%$ of cancer patients will undergo radiotherapy, which is considered to be an effective treatment modality for locally advanced cervical cancer (4).

During conventional radiotherapy, most of the X-ray energy or $\gamma$-irradiation is deposited in normal tissue before reaching tumors, therefore, it may not be possible to deliver sufficient radiation target doses using single-field irradiation (5). As an advancement of current radiotherapy approaches, ${ }^{12} \mathrm{C}^{6+}$ radiotherapy provides a promising therapeutic option for various malignancies resistant to conventional photon radiotherapy. The unique factors that improve the killing effects on tumor cells when compared to X-ray or $\gamma$-irradiation include: i) superior physical dose distribution as a result of the spread-out Bragg peak effect (6), enabling radiation to intensively target cancer cells while sparing surrounding tissues $(7,8)$; ii) increased relative biological effectiveness (9); iii) lower oxygen enhancement ratios and almost constant radio-sensitivity within the cell cycle $(10,11)$, thereby inducing more cell cycle- and oxygenation-independent, irreparable DNA damage, and killing more radio-resistant tumor cells than photon beams (12). A large body of evidence has revealed that ${ }^{12} \mathrm{C}^{6+}$ radiation exhibits strong cell-killing effects, approximately 2-3 times greater than photon techniques $(13,14)$. Ever since the first clinical experience in 1977 , approximately 20,000 patients worldwide have received ${ }^{12} \mathrm{C}^{6+}$ radiotherapy, with patient numbers growing steadily $(15,16)$. In spite of heavy-ion therapy alone exhibiting favorable therapeutic effects on a variety of tumors, the approach does not achieve a satisfactory overall 5-year survival rate for patients with cervical cancer (17). Thus, there is a growing interest in combined modalities for cervical cancer, especially for molecularly targeted therapies. 
The Wnt/ $\beta$-catenin signaling pathway is crucial during cell development, and is implicated in numerous biological events, including embryogenesis, cell proliferation (18), invasion (19), apoptosis, and cellular differentiation $(20,21)$. During normal adult stage, the Wnt signaling pathway is inactive or silent. However, once the body is stimulated by inflammation, neurological disease and cancer, Wnt signaling becomes dysregulated $(22,23)$. Accumulating evidence suggests that the canonical Wnt signaling pathway is indispensable for tumorigenesis and tumor propagation (24). Activation of Wnt signaling contributes to tumor proliferation and metastasis, while Wnt signaling suppression blocks cancer stemness, and induces cell senescence (25). Previous studies have revealed that activation of the $\mathrm{Wnt} / \beta$-catenin signaling pathway is implicated in a number of tumor types, such as gastrointestinal, breast, melanoma, glioblastoma (26), colorectal, lung and liver $(27,28)$. Moreover, it has been reported that the aberrant activation of canonical Wnt signaling is involved in the multistep pathogenesis and progression of cervical cancer $(29,30)$. Previously, we demonstrated that Wnt signaling pathway inhibition enhances radiosensitivity in human cervical cancer HeLa cells (31). Thus, the Wnt/ $\beta$-catenin signaling pathway is involved in the tumorigenesis of numerous cancers, indicating its potential value as a target for cancer treatment.

HLY78 is a new small-molecule activator of the Wnt/ $\beta$-catenin signaling pathway, that acts in a Wnt ligand-dependent manner. Mounting evidence suggests that HLY78 directly binds to the DAX domain of Axin, enhancing the interaction of Axin-LRP6, which promotes LRP6 phosphorylation and Wnt signal transduction (32-34). A previous study has revealed that zebrafish embryo supplementation with HLY78 significantly reduced developmental toxicity induced by carbon ion radiation alone (34). Although the protective effects of HLY78 on cancer cell damage have been reported, its effects on ionizing radiation (IR)-induced damage have not been well defined.

In the present study, a HeLa cell model was used to explore Wnt signaling pathway functions in cervical cancer progression. To provide a biological basis for the combined use of the Wnt agonist with ${ }^{12} \mathrm{C}^{6+}$ beam radiotherapy, the effects of HLY78 on IR-induced damage in HeLa cells was evaluated. These findings may provide new insights into potential therapeutic applications relevant to the Wnt signaling pathway.

\section{Materials and methods}

Cell culture and treatments. Human cervical carcinoma cells (HeLa) were gifted by the First Hospital of Lanzhou University, and cultured in Dulbecco's modified Eagle's medium (DMEM), supplemented with $10 \%$ fetal bovine serum (FBS; both from HyClone ${ }^{\mathrm{TM}}$; GE Healthcare Life Sciences). All cells were maintained in a humidified $5 \% \mathrm{CO}_{2}$ atmosphere at $37^{\circ} \mathrm{C}$.

Chemical and irradiation exposure. HeLa cells in exponential growth were cultured in 35-mm culture dishes, and incubated overnight to facilitate adherence. The Wnt activator, HLY78 (purity $\geq 98 \%$ ) was dissolved in dimethyl sulfoxide (DMSO; both from Sigma-Aldrich; Merck KGaA). Cells were pre-incubated with DMSO and HLY78 for $2 \mathrm{~h}$ before ${ }^{12} \mathrm{C}^{6+}$ irradiation, and maintained in the medium until the samples were collected.

Then, HeLa cells were exposed to ${ }^{12} \mathrm{C}^{6+}$ beam at an energy of $80 \mathrm{MeV} / \mathrm{u}$ and linear energy transfer (LET) of $50 \mathrm{keV} / \mu \mathrm{m}$, with a dose rate of $4 \mathrm{~Gy} / \mathrm{min}$. Heavy-ion beam irradiation was performed at the Heavy Ion Research Facility in Lanzhou (HIRFL; Institute of Modern Physics, Chinese Academy of Sciences, Lanzhou, China). All experiments were separately completed three times.

Cell Counting Kit-8 (CCK-8) cell viability assay. Cells from various treatment groups (control, HLY78, IR, IR+HLY78) were transferred to 96-well plates at a density of 3,000 cells/ well, and cultured for $6,12,24,48,72$ and $96 \mathrm{~h}$ in a humidified $5 \% \mathrm{CO}_{2}$ incubator. At the end of incubation, $20 \mu \mathrm{l} \mathrm{CCK}-8$ (Dojindo Molecular Technologies, Inc.) reagent was added to each well $2 \mathrm{~h}$ before assaying. Cell viability was determined by colorimetry, with optical density at $450 \mathrm{~nm}$ measured on a microplate reader (Tecan Infinite $200 \mathrm{M}$ ).

Clonogenic survival assay. Immediately after irradiation, cells from various treatment groups (control, HLY78, IR, IR+HLY78) were detached and plated in triplicate onto $60-\mathrm{mm}$ culture dishes at 1,000 cells/well. All cells were cultured for 10-14 days at $37^{\circ} \mathrm{C}$ in a humidified $5 \% \mathrm{CO}_{2}$ incubator. After this period, surviving colonies were fixed in ice-cold $4 \%$ paraformaldehyde for $15 \mathrm{~min}$, and then stained with $1 \%$ crystal violet for $20 \mathrm{~min}$. The number of colonies containing at least 50 cells were scored as surviving units. Plating efficiency (PE) was calculated as the number of colonies formed, divided by the cell inoculation number in the control. The surviving fraction (SF) of the irradiated group was defined as: SF = colonies counted/(cells seeded x PE). The parameters of the survival curve were determined using a linear-quadratic equation.

Cell apoptosis assay. Following incubation for $24 \mathrm{~h}$ at $37^{\circ} \mathrm{C}$, various treatment group of cells (control, HLY78, IR, IR+HLY78) were detached and washed twice in chilled PBS, diluted to $100 \mu \mathrm{l}$ in $1 \mathrm{X}$ binding buffer, then mixed with $5 \mu \mathrm{l}$ FITC Annexin V and $5 \mu \mathrm{l}$ propidium iodide (PI) (Annexin V-FITC Apoptosis Detection Kit I; BD Biosciences). Samples were incubated in the dark for $15 \mathrm{~min}$ at $25^{\circ} \mathrm{C}$, after which flow cytometry (Amnis FlowSight; Luminex Corporation) was performed to quantify cell apoptosis. A minimum of 10,000 cells were counted in each sample. IDEAS Application v6.0 (Merck Millipore) software was used to identify apoptotic cells.

Cell cycle assay. After incubation for $24 \mathrm{~h}$ at $37^{\circ} \mathrm{C}$, various treatment group of cells (control, HLY78, IR, IR+HLY78) were detached and fixed overnight in ice-cold $70 \%$ ethanol at $-20^{\circ} \mathrm{C}$. Then, the cells were centrifuged at $1,000 \mathrm{rpm}$ for $4 \mathrm{~min}$, and the supernatant was removed. To the pellet, $2-5 \mathrm{ml}$ PBS was added to rehydrate the cells for $15 \mathrm{~min}$. Finally, the cells were gently resuspended in $75 \mu$ l DNA staining solution (MultiSciences Biotech Co., Ltd.) for $30 \mathrm{~min}$, and maintained in the dark at room temperature (RT) until analysis. Data were processed using FlowJo-V10 software (FlowJo, LLC) with at least 10,000 cells examined per sample. 

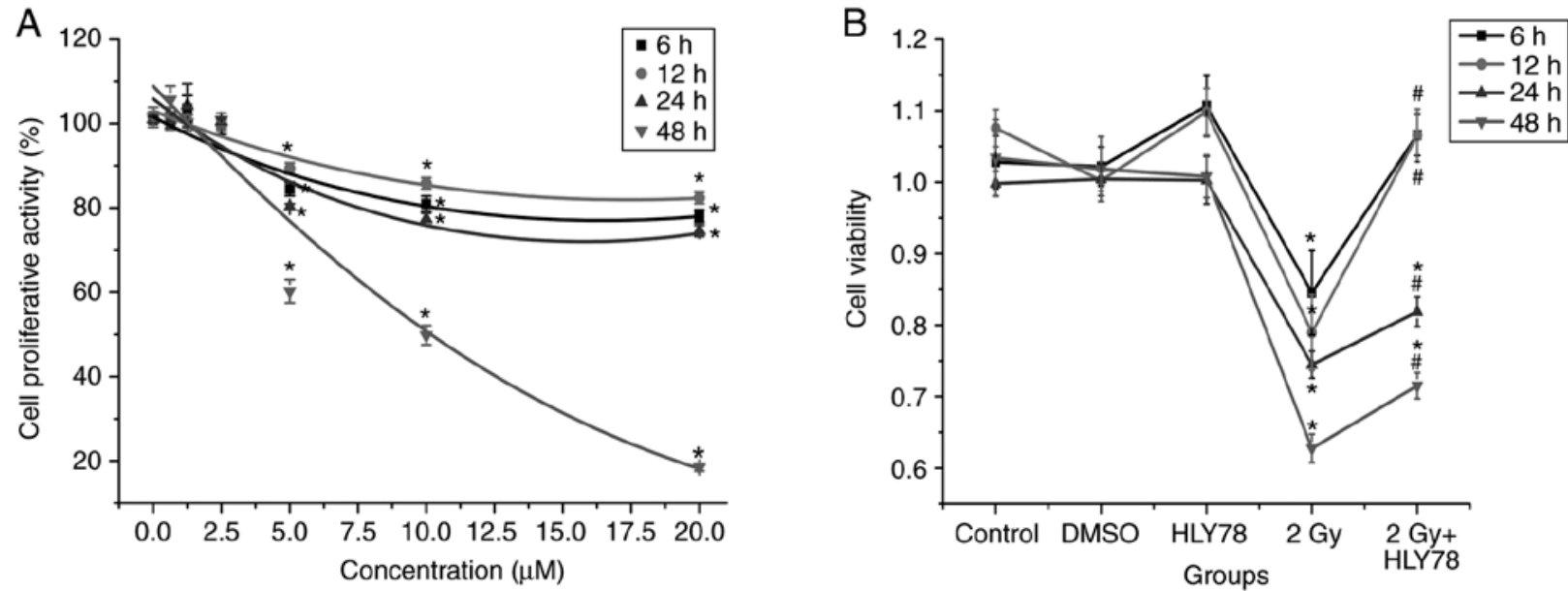

Figure 1. HLY78 attenuates the inhibitory effects of ${ }^{12} \mathrm{C}^{6+}$ radiation on cell viability in human cervical carcinoma, HeLa cells. (A) A CCK-8 assay revealing cell proliferation affected by various HLY78 concentrations. (B) Cell viability at $6,12,24$ and $48 \mathrm{~h}$ after ${ }^{12} \mathrm{C}^{6+}$ radiation, as assessed by CCK- 8 assay. The line chart shows cell viability when exposed to 2 Gy high-LET ${ }^{12} \mathrm{C}^{+}$beam, with or without $2.5 \mu \mathrm{M}$ HLY78 administration, respectively. Data are expressed as the mean \pm SEM, from triplicate experiments. ${ }^{*} \mathrm{P}<0.05$ (vs. the control group). ${ }^{~} \mathrm{P}<0.05$ (vs. the radiation group). CCK-8, Cell Counting Kit- 8 ; LET, linear energy transfer.

Immunofluorescence. Phosphorylated histone $\mathrm{H} 2 \mathrm{AX}$ $(\gamma-\mathrm{H} 2 \mathrm{AX})$ and cytosolic and nuclear $\beta$-catenin expression in HeLa cells was detected using immunofluorescence. After irradiation for $4 \mathrm{~h}$, cells were exposed to various treatments (control, HLY78, IR, IR+HLY78) and fixed overnight at $4^{\circ} \mathrm{C}$ in $4 \%$ paraformaldehyde. The following day, the cells were permeabilized with $0.5 \%$ Triton X-100 for $5 \mathrm{~min}$, and rinsed three times in PBS, followed by blocking in $10 \%$ bovine serum albumin (BSA) in TBS with $0.1 \%$ Tween-20 (TBST) for $1 \mathrm{~h}$ at RT. Subsequently, the cells were incubated with rabbit anti- $\gamma$-H2AX (1:200; ab11174) (Abcam), or anti- $\beta$-catenin (1:300; GTX26302) (GeneTex, Inc.) overnight at $4^{\circ} \mathrm{C}$, and then the cells were incubated with a 1:1,000 dilution of FITC-labelled secondary antibody, goat anti-rabbit $\operatorname{IgG}(\mathrm{H} \& \mathrm{~L})$ (cat. no. RS3211; ImmunoWay Biotechnology Company) for $1 \mathrm{~h}$ in the dark. Cells were counterstained with DAPI (Vector Laboratories, Inc.) for nuclear staining. A Zeiss LSM-700 confocal microscope (Carl Zeiss AG) captured cell images (magnification, $\mathrm{x} 400$ ).

Western blotting. Following ${ }^{12} \mathrm{C}^{6+}$ irradiation for $24 \mathrm{~h}$, cells (treated and untreated) were lysed in RIPA buffer (Beijing Solarbio Science \& Technology Co, Ltd.) supplemented with protease inhibitors for $30 \mathrm{~min}$ on ice. Protein concentrations were quantified using the $\mathrm{BCA}^{\mathrm{TM}}$ protein assay kit (Pierce; Thermo Fisher Scientific, Inc.). Equivalent protein lysates $(30 \mu \mathrm{g})$ were fractionated on 15\% SDS-PAGE and transferred to PVDF membranes (EMD Millipore). To prevent non-specific binding, the membranes were first blocked in TBST containing $5 \%$ BSA for $1 \mathrm{~h}$ at RT, and then probed with primary rabbit antibodies for anti-p53 (1:1,000; cat. no. GTX50438), anti-Bax (Bcl-2-Associated X protein) (1:500; cat. no. GTX32465), anti-Bcl-2 (B-cell lymphoma-2) (1:500; cat. no. GTX100440), anti-Wnt5a (1:500; cat. no. GTX111187), anti-Wnt3a (1:1000; cat. no. GTX128101) and anti- $\beta$-catenin ( $1: 4000$; cat. no. GTX26302) (all from GeneTex, Inc.) at $4^{\circ} \mathrm{C}$ overnight. After washing three times in TBST for $15 \mathrm{~min}$, the corresponding HRP-conjugated secondary antibody, goat anti-rabbit IgG (H+L) (1:10,000; cat. no. BS13278; Bioworld Technology, Inc.) was added to membranes and incubated for $1 \mathrm{~h}$ at RT. Subsequently, the protein expression was visualized by ECL reagent (WBKLS0500; EMD Millipore). Densitometric analysis was performed using the AlphaView imaging software (version 3.4.0; ProteinSimple). GAPDH (1:5,000; cat. no. GTX100118; GeneTex, Inc.) was used as a loading control to normalize data.

Statistical analyses. All assays were repeated at least three times and values were presented as the mean \pm standard error of the mean (SEM). Statistical analyses were performed using IBM SPSS Statistics 20 software (IBM, Corp.). One-way analysis of variance (ANOVA), with Tukey's post hoc tests were applied to detect statistically significant differences between groups. Differences with a P-value $<0.05$ were considered statistically significant. Figures were plotted using Origin 8.0 (OriginLab).

\section{Results}

Determination of optimal HLY78 concentrations in HeLa cells. Firstly, HLY78 cytotoxicity was evaluated in HeLa cells over the dose range, $0.625-20 \mu \mathrm{M}$. A CCK-8 assay indicated that cell viability was significantly decreased between 2.5-20 $\mu \mathrm{M}$, and that the decrease was dose-dependent. There were no obvious toxic effects at doses $<2.5 \mu \mathrm{M}$ in comparison with the control cells (Fig. 1A), therefore, $2.5 \mu \mathrm{M}$ HLY78 was used for all subsequent experiments in cells.

Combinatorial effects of ${ }^{12} \mathrm{C}^{6+}$ radiation and $\mathrm{HLY} 78$ on $\mathrm{HeLa}$ cell viability. To investigate the effects of HLY78 on HeLa cells exposed to high-LET ${ }^{12} \mathrm{C}^{6+}$ beams, cell viability was assessed after irradiation at $2 \mathrm{~Gy}{ }^{12} \mathrm{C}^{6+}$ beams. The present data revealed a significant difference in cell viability among groups $(\mathrm{P}<0.05) .{ }^{12} \mathrm{C}^{6+}$ radiation induced a significant decrease in cell viability, whereas the addition of HLY78 markedly attenuated the cellular inhibitory effects induced by irradiation 

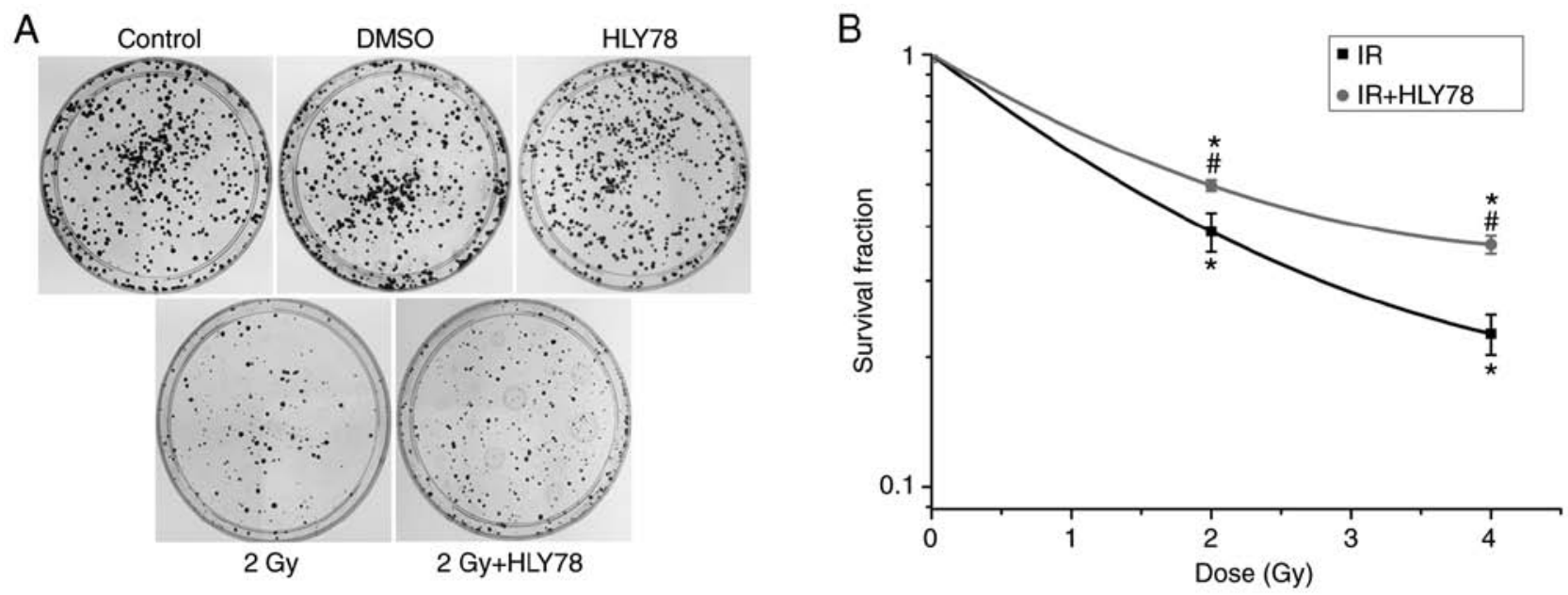

Figure 2. HLY78 protects HeLa cells from cellular toxicity after ${ }^{12} \mathrm{C}^{6+}$ radiation. (A) Representative images from colony formation assays of proliferating HeLa cells treated with HLY78, and exposed to ${ }^{12} \mathrm{C}^{6+}$ radiation. (B) Surviving fraction of cells, with and without $\mathrm{HLY} 78$ after ${ }^{12} \mathrm{C}^{6+}$ radiation. HeLa cells were plated immediately after ${ }^{12} \mathrm{C}^{6+}$ beam alone, or in combination with $2.5 \mu \mathrm{M}$ HLY78 for 14 days. Data are expressed as the mean \pm SEM, from triplicate experiments. Three independent measurements were performed, each in triplicate. ${ }^{*} \mathrm{P}<0.05$ (vs. the control group). ${ }^{*} \mathrm{P}<0.05$ (vs. the radiation group).

alone $(\mathrm{P}<0.05)$. The results $($ Fig. $1 \mathrm{~B})$ revealed that treatment with both DMSO and HLY78 alone had no effects on cell proliferation within $48 \mathrm{~h}$, when compared with the controls $(\mathrm{P}>0.05)$. Cell viability was reduced by $\sim 40.62 \%(\mathrm{P}<0.05)$ at $48 \mathrm{~h}$ after ${ }^{12} \mathrm{C}^{6+}$ irradiation when compared with the controls. For cells administered HLY78 plus irradiation, viability was significantly increased from $62.77 \pm 1.98$ to $71.53 \pm 1.83 \%$ $(\mathrm{P}<0.05)$ when compared with irradiation-only cells. These data indicated that HLY78 protects HeLa cells from cellular toxicity after ${ }^{12} \mathrm{C}^{6+}$ radiation.

HeLa cytotoxicity at $2 \mathrm{~Gy}{ }^{12} \mathrm{C}^{6+}$ irradiation alone, and in combination with HLY78 was evaluated by clonogenic survival assay. The results (Fig. 2) revealed that treatment with HLY78 alone exerted no notable effects on colony forming efficiency. Moreover, there was a significant decrease in colonies formed in the radiation group at 2 and 4 Gy $(\sim 2.57$ - and 4.42-fold, respectively), in comparison with the control group $(\mathrm{P}<0.05)$. However, when ${ }^{12} \mathrm{C}^{6+}$ beam-exposed HeLa cells were pre-treated with HLY78, colony formation efficiency was increased when compared with the irradiation alone cells (from $38.96 \pm 4.00$ to $49.78 \pm 1.45 \%$ for $2 \mathrm{~Gy}+\mathrm{HLY} 78$; and $22.60 \pm 4.39$ to $36.32 \pm 1.72 \%$ for $4 \mathrm{~Gy}+\mathrm{HLY} 78$ respectively) (Fig. 2B), indicating that HLY78 decreased radiation-induced radio-sensitivity.

Combinatorial effects of carbon ion radiation and HLY78 on Wnt-related protein expression in HeLa cells. Western blotting evaluated the net effects of combined HLY78 and ${ }^{12} \mathrm{C}^{6+}$ radiation on Wnt-related protein expression in HeLa cells. The present data indicated that HLY78 alone induced a significant increase in $\beta$-catenin (1.94-fold, $\mathrm{P}<0.05)$, Wnt3a (1.59-fold, $\mathrm{P}<0.05)$ and $\mathrm{Wnt5a}(1.39$-fold, $\mathrm{P}<0.05)$ expression, relative to the control group. Moreover, when compared with HeLa cells treated with ${ }^{12} \mathrm{C}^{6+}$ beam alone, $\beta$-catenin, Wnt3a and Wnt5a expression levels were increased by $\sim 1.70-, 1.53$ - and 1.83 -fold, respectively in HeLa cells that received combined treatment of HLY78 after radiation (Fig. 3A and B). Moreover, immunofluorescence staining was used to examine the expression and location of $\beta$-catenin in HeLa cells treated with the HLY78-irradiation combination. These data revealed that HLY78 significantly reduced the inhibitory effects of the ${ }^{12} \mathrm{C}^{6+}$ beam on nuclear $\beta$-catenin protein expression in HeLa cells (Fig. 3C and D). Thus, HLY78 may protect HeLa cells from IR-induced damage by promoting Wnt-related protein expression. Collectively, these data indicated that the Wnt signaling pathway was responsible for the radio-sensitivity of HeLa cells.

Combinatorial effects of carbon ion radiation and HLY78 on cell cycle progression in HeLa cells. Increasing evidence suggests that alterations in cell cycle distribution post-irradiation, are closely associated with sensitivity in tumor cell lines (35). Hence, the effects of ${ }^{12} \mathrm{C}^{6+}$ radiation alone and in combination with HLY78 on cell cycle progression were examined by flow cytometry after irradiation for $24 \mathrm{~h}$. The results (Fig. 4) revealed that treatment with HLY78 alone without radiation, did not induce an appreciable G2/M arrest. However, the proportion of cells in the G2/M phase increased upon ${ }^{12} \mathrm{C}^{6+}$ radiation alone, when compared with the control $(33.30 \pm 1.60$ vs. $21.70 \pm 1.00 \%, \mathrm{P}<0.05)$. In addition, a significant decrease was observed in the proportion of cells in the $\mathrm{G} 2 / \mathrm{M}$ phase $(23.70 \pm 2.20$ vs. $33.30 \pm 1.60 \%, \mathrm{P}<0.05)$ after combined treatment with radiation and HLY78, when compared with cells exposed to ${ }^{12} \mathrm{C}^{6+}$ radiation alone.

Combinatorial effects of carbon ion radiation and HLY78 on DNA damage in HeLa cells. The expression of $\gamma$-H2AX expression, which is an important biomarker of DNA double-strand breaks (DSBs), was assessed after irradiation treatment. Immunofluorescence was used to examine the effects of HLY78 on the accumulation of DNA damage in irradiated HeLa cells. The results (Fig. 3E and F) revealed that the addition of HLY78 significantly decreased $\gamma$-H2AX expression, when compared with cells that received ${ }^{12} \mathrm{C}^{6+}$ radiation alone. These data indicated that HLY78 potentially blocked the accumulation of unrepaired lethal DNA lesions to protect HeLa cells from radiation-induced damage. 

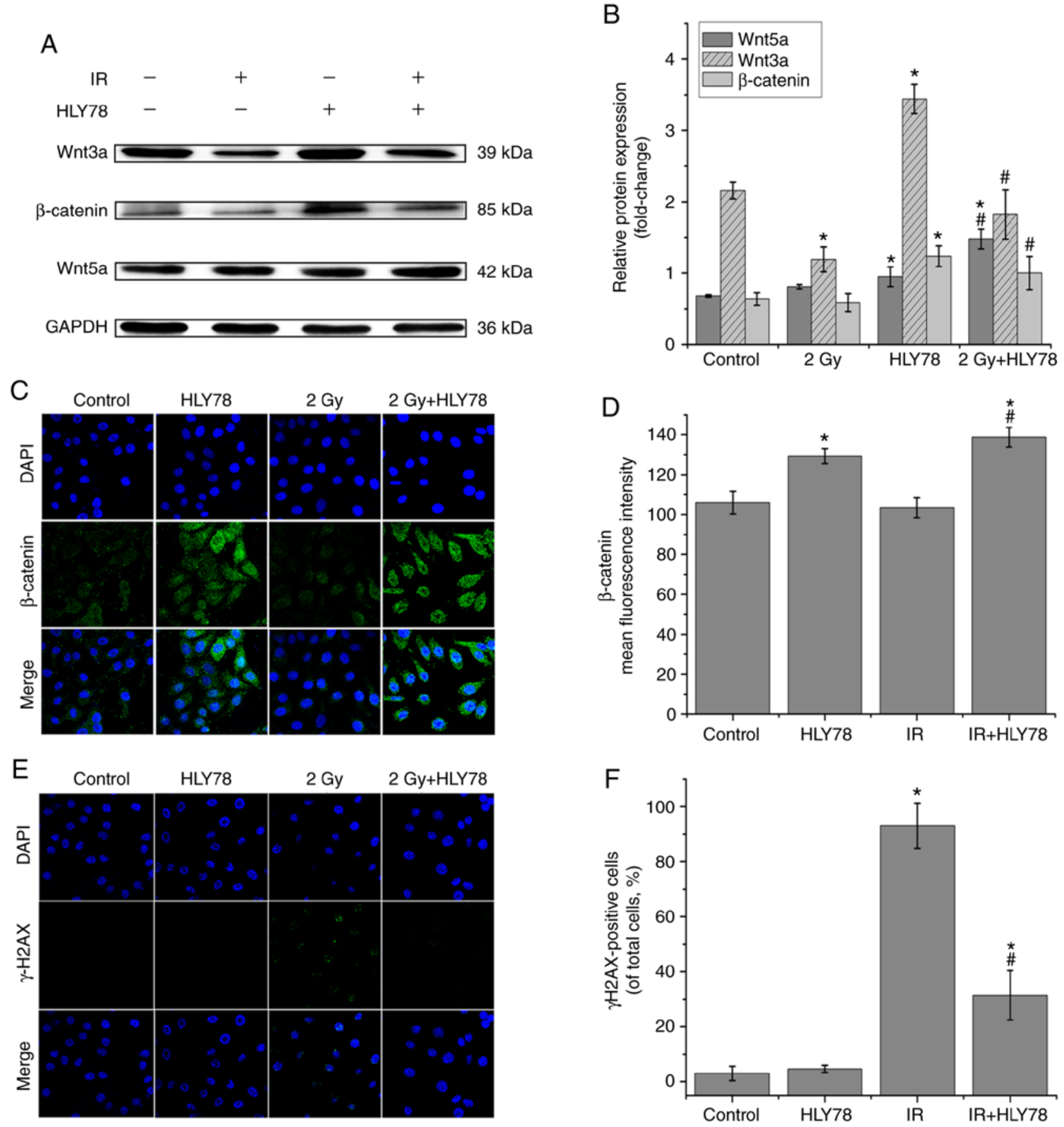

Figure 3. HLY78 promotes cervical cancer progression by altering Wnt-related protein expression. (A) Representative western blot images. (B) Quantitative analysis of Wnt5a, Wnt3a and $\beta$-catenin protein expression in HeLa cells after treatment with HLY78 alone, or combined with ${ }^{12} \mathrm{C}^{6+}$ radiation for $24 \mathrm{~h}$. GAPDH was used as a loading control. (C) The effects of HLY78 on the subcellular localization of $\beta$-catenin (green) in HeLa cells after exposure to ${ }^{12} \mathrm{C}^{6+}$ radiation for $4 \mathrm{~h}$, using confocal microscopy. Nuclei are counterstained with DAPI (blue). (D) The mean fluorescence intensity of $\beta$-catenin in various treatment groups. (E) Phosphorylation levels of $\gamma$-H2AX in various treatment groups were assessed by immunofluorescence. Representative confocal microscopy images are presented. (F) The percentage of $\gamma$-H2AX-positive cells in total cells. $\gamma-\mathrm{H} 2 \mathrm{AX}$, phosphorylated histone $\mathrm{H} 2 \mathrm{AX}$. All experiments were performed in triplicate. Values are expressed as the mean \pm SEM. ${ }^{*} \mathrm{P}<0.05$ (vs. the control group). ${ }^{*} \mathrm{P}<0.05$ (vs. the radiation group).

Combinatorial effects of carbon ion radiation and HLY78 on HeLa apoptosis. Apoptotic HeLa cells were assessed using flow cytometry, after irradiation with $2 \mathrm{~Gy}{ }^{12} \mathrm{C}^{6+}$ beam for $24 \mathrm{~h}$. The results (Fig. 5A and B) revealed that treatment with HLY78 in the absence of ${ }^{12} \mathrm{C}^{6+}$ beam irradiation, exerted no significant changes in HeLa apoptosis. However, a significant increase was observed in apoptosis after ${ }^{12} \mathrm{C}^{6+}$ irradiation, when compared with the control $(17.95 \pm 1.25$ vs. $1.97 \pm 0.42 \%$,
$\mathrm{P}<0.05$, respectively). When compared to the irradiation group alone, the combined treatment, HLY78 and radiation group generated a significant decrease in apoptosis, and thus an advantage for HeLa cell survival (17.95 \pm 1.25 vs. $5.63 \pm 0.47 \%$, $\mathrm{P}<0.05)$.

Since HLY78 administration had significant responses in ${ }^{12} \mathrm{C}^{6+}$ radiation-induced apoptosis, the potential functional mechanisms were investigated. Induction of apoptosis by ${ }^{12} \mathrm{C}^{6+}$ 

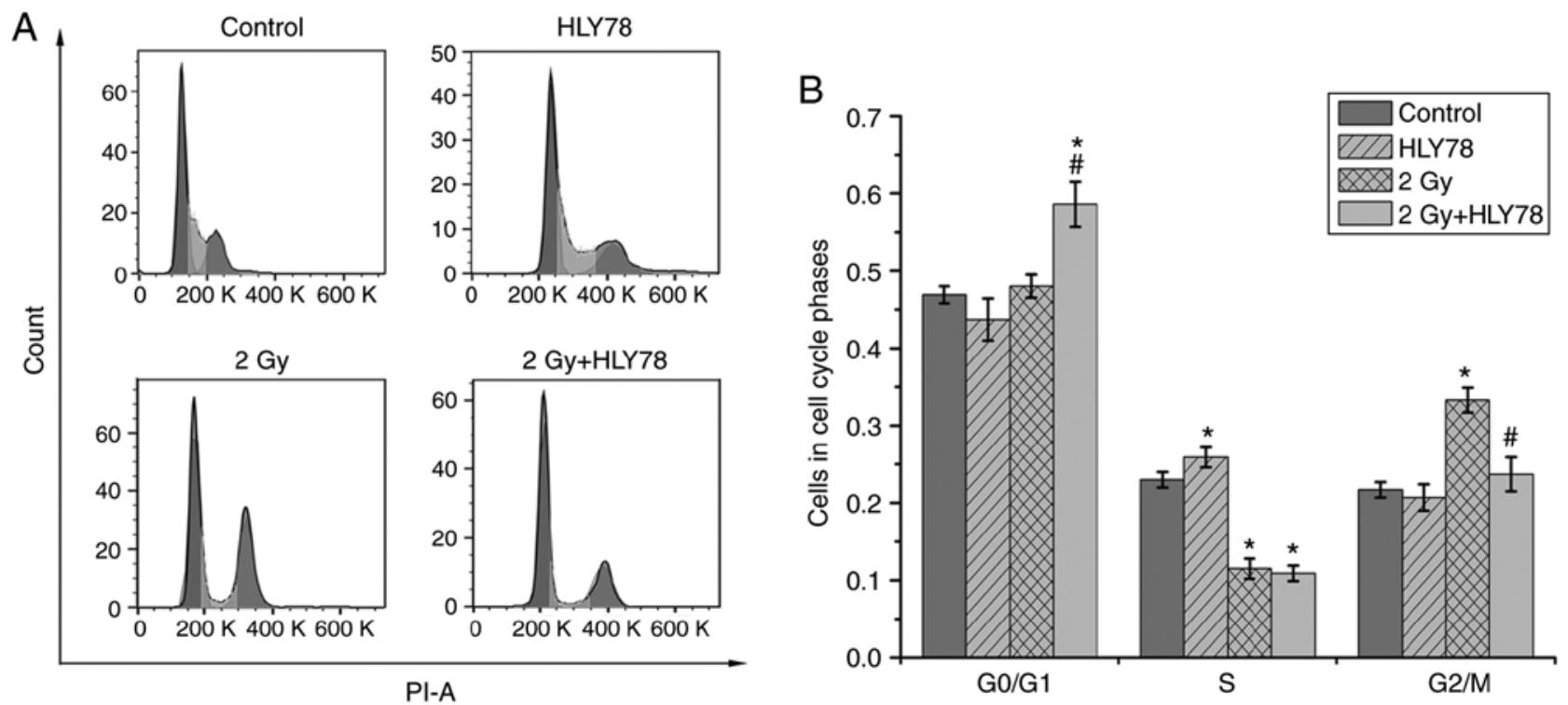

Figure 4. HLY78 inhibits the G2/M phase arrest in HeLa cells induced by 2 Gy high-LET ${ }^{12} \mathrm{C}^{6+}$ beam. (A) Representative cell cycle distribution images in stained cells, with irradiation alone or combined with HLY78. (B) Bar graph revealing the percentage of cells in the G0/G1, S and G2/M phases at 24 h after exposure to $2 \mathrm{~Gy}$ of the ${ }^{12} \mathrm{C}^{6+}$ beam. Data are presented as the mean $\pm \mathrm{SEM}$ of three independent experiments. ${ }^{*} \mathrm{P}<0.05$ (vs. the control group). ${ }^{\#} \mathrm{P}<0.05$ (vs. the radiation group). LET, linear energy transfer.

radiation, with or without HLY78, was analyzed by western blotting. As revealed in Fig. 5C and D, in cells treated with HLY78 immediately after ${ }^{12} \mathrm{C}^{6+}$ irradiation, p53 and Bax expression were significantly decreased (by $\sim 1.40$ - and 1.21-fold, respectively, $\mathrm{P}<0.05$ ), whereas $\mathrm{Bcl}-2$ expression was significantly increased (by $\sim 1.44$-fold, $\mathrm{P}<0.05$ ), when compared to cells receiving the ${ }^{12} \mathrm{C}^{6+}$ beam alone. These data indicated that the canonical Wnt signaling pathway effectively regulated irradiation-induced apoptosis in HeLa cells.

\section{Discussion}

Although ${ }^{12} \mathrm{C}^{6+}$ radiotherapy has become a promising therapeutic option for locally advanced cervical cancer, due to its unique physical and biological effects, the 5-year survival rate for patients is unsatisfactory. Therefore, there is an urgent need to identify effective therapeutic targets to improve efficacy approaches for cervical cancer. Previously, aberrant activation of the Wnt/ $\beta$-catenin signaling pathway was implicated in the initial steps and progression of a variety of cancers, including cervical cancer (36). HLY78, as a small-molecule activator of the Wnt $/ \beta$-catenin pathway protects cancer cells against damage; HLY78 was revealed to exert cytoprotective effects against resveratrol-induced cellular toxicity in breast cancer cell lines (37). However, its effects on ${ }^{12} \mathrm{C}^{6+}$ radiation-induced damage in HeLa cells are unknown.

HLY78 was used to improve our understanding of the Wnt/ $\beta$-catenin signaling pathway in regulating irradiation-induced toxicity in HeLa cells. A previous study indicated that the upregulation of the Wnt pathway by HLY78, significantly attenuated decreases in gastric cancer cell viability, induced by the overexpression of oxysterol-binding protein-related protein 8 (ORP8) (38). Moreover, other studies have indicated that $\mathrm{Wnt} / \beta$-catenin pathway activation promotes cell growth and proliferation in cervical cancer (39).
Considering that HLY78 may have protective effects on irradiated HeLa cells, HLY78-mediated cytotoxicity in these cells was firstly evaluated using a CCK- 8 assay. The present data data indicated that increasing drug concentrations (2.5, 5,10 and $20 \mu \mathrm{M}$ ) caused cell proliferation to decrease in a dose-dependent manner. Similarly, there were no significant differences in cell proliferation rates as incubation duration increased $(6,12,24$, and $48 \mathrm{~h})$. Therefore, HLY78 at $2.5 \mu \mathrm{M}$ was used in the present study.

Continuous activation of $\mathrm{Wnt} / \beta$-catenin signaling is closely related to the uncontrolled, self-renewal of tumor cells $(24,40)$. The present study also demonstrated that cell viability decreased after ${ }^{12} \mathrm{C}^{6+}$ irradiation at a dose of $2 \mathrm{~Gy}$, when compared with control cells. Notably, this decrease in cell viability was effectively alleviated by HLY78, indicating that HLY78 exerted protective effects against radiation-induced damage. Similar data were observed for the colony-formation abilities of HeLa cells treated with HLY78 and irradiation; colony forming efficiencies were increased in comparison with radiation alone. These observations agreed with previous research which revealed that the aberrant activation of the Wnt/ $\beta$-catenin pathway could prevent radiation-induced damage to salivary glands (41), and rescue intestinal stem cells against radiation (42). Similarly, another study identified HLY78 as having a protective role against ${ }^{12} \mathrm{C}^{6+}$ radiation-induced developmental toxicity in zebrafish (33). Collectively, these results indicated that the Wnt signaling pathway is implicated in ${ }^{12} \mathrm{C}^{6+}$ radiation-induced cytotoxicity.

Next, the possible mechanisms behind HLY78-mediated protective effects were explored. Increasing evidence has revealed that HLY78 acts upstream of the $\beta$-catenin degradation complex, and functions by stabilizing cytosolic and nuclear $\beta$-catenin in the presence of the Wnt3a ligand (43). $\beta$-Catenin is known as the central effector of the canonical 
A

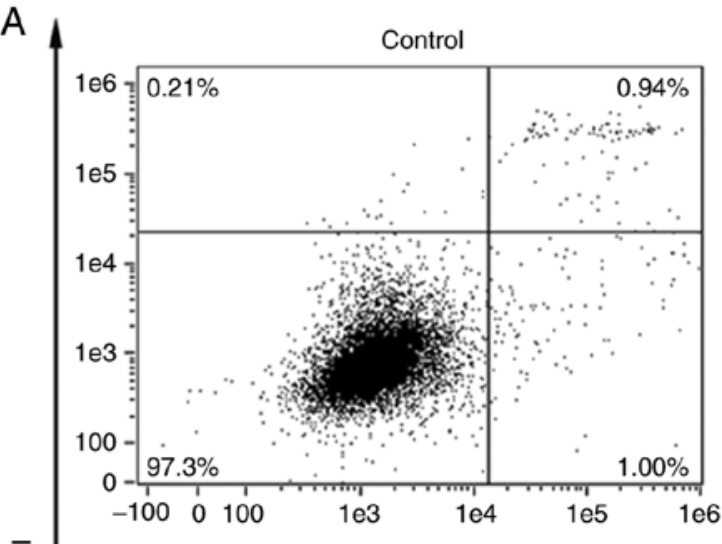

$\overline{2}$

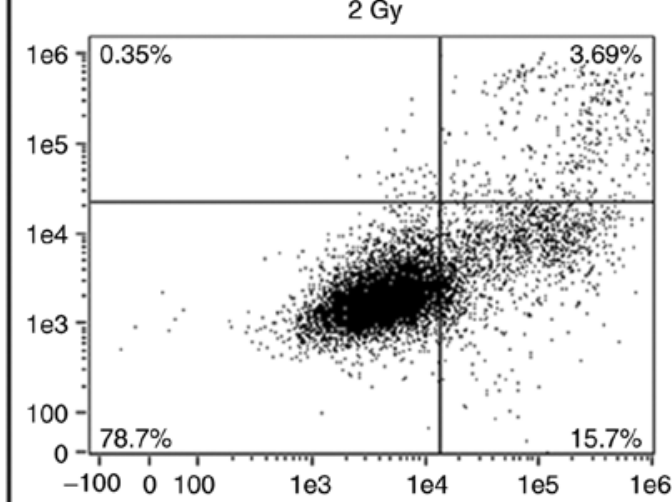

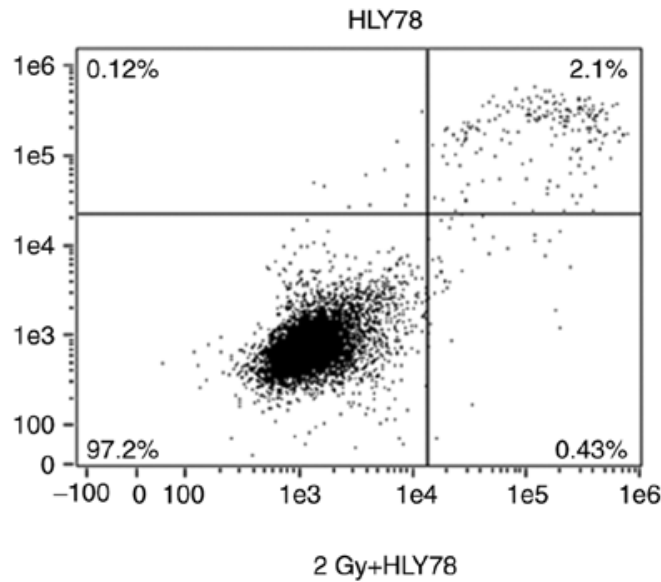

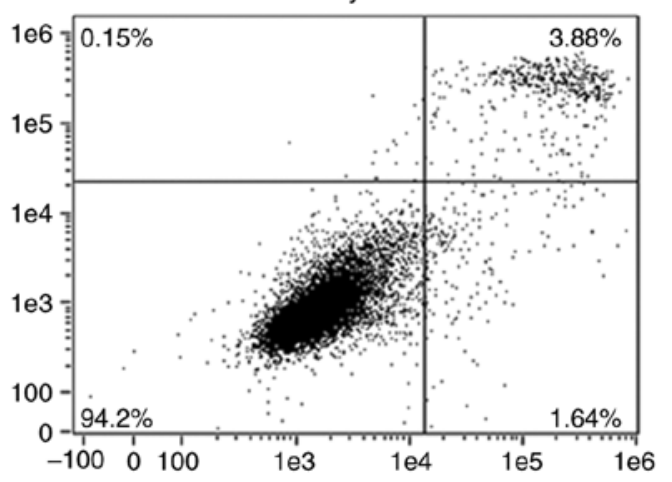

Annexin V-FITC
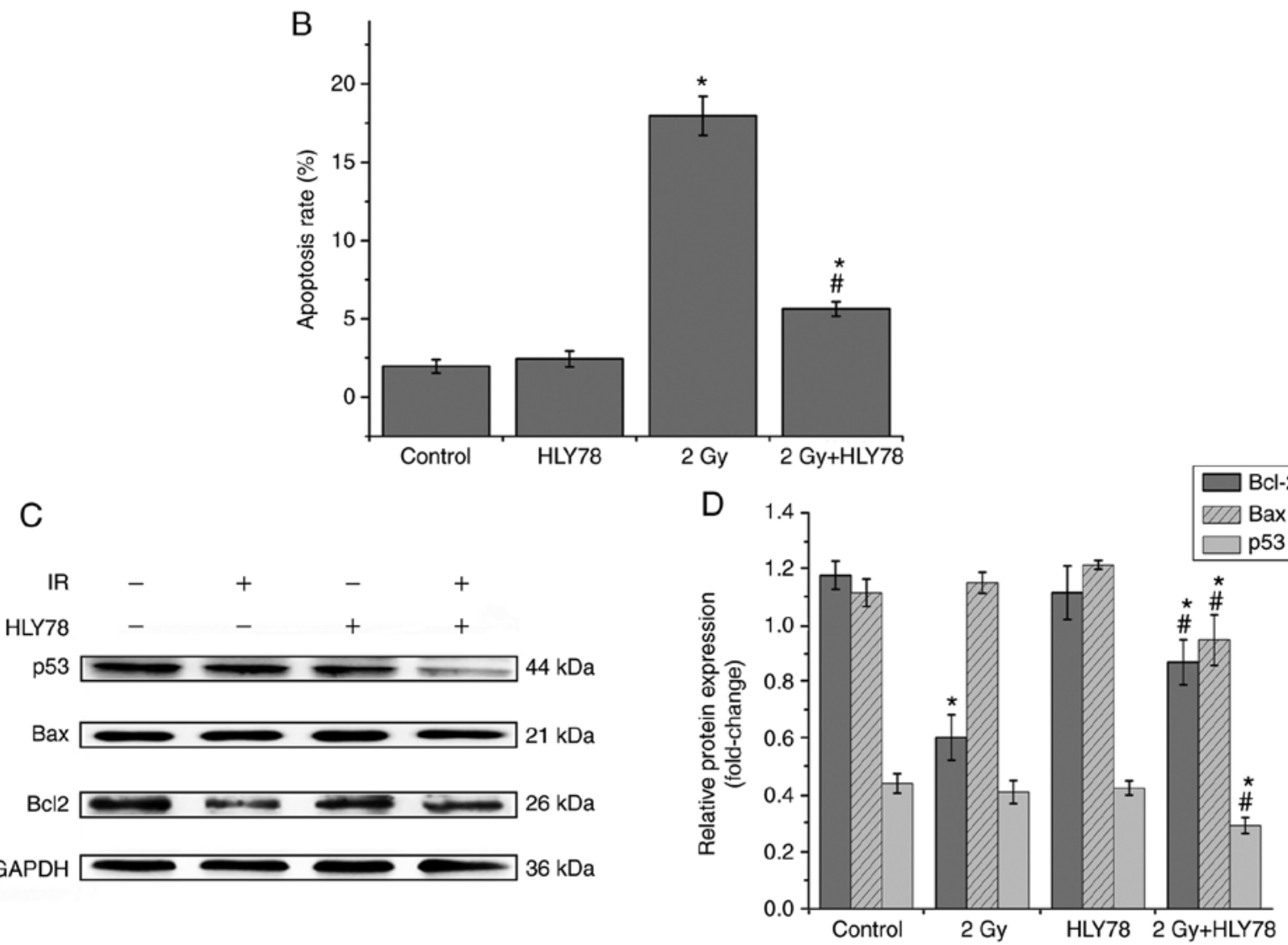

Figure 5. HLY78 effectively inhibits irradiation-induced apoptosis in HeLa cells. (A) Cells were cultured under various treatments for $24 \mathrm{~h}$, and cell apoptosis was assessed using Annexin V-FITC and PI double-staining flow cytometry. (B) Quantitative analysis of cell apoptosis percentages when treated with ${ }^{12} \mathrm{C}^{6+}$ radiation alone, or combined with HLY78 in cells. (C) Bcl-2, Bax and p53 expression levels were assessed by western blotting in cells. GAPDH was used as a loading control. (D) Bar chart representing the quantification of western blotting protein signals. Data are presented as the mean \pm SEM from three independent experiments. ${ }^{*} \mathrm{P}<0.05$ (vs. the control group). ${ }^{*} \mathrm{P}<0.05$ (vs. the radiation group). Bcl-2, B-cell lymphoma-2; Bax, Bcl-2-Associated $\mathrm{X}$ protein 
Wnt signaling pathway, thus when the Wnt/ $\beta$-catenin pathway is activated, $\beta$-catenin translocates to the nucleus from the cytoplasm in coordination with the TCF/LEF complex and co-activators, to regulate the expression of downstream target genes $(39,44)$. Research has revealed that high levels of $\beta$-catenin are expressed during tumor progression in cervical cancer tissues (45), and the protein is a poor prognostic factor of cervical carcinoma (27). Furthermore, HLY78 protected zebrafish embryos from IR-induced damage, by activating the $\mathrm{Wnt} / \beta$-catenin pathway (34). In the present study, the expression levels of Wnt-related proteins ( $\beta$-catenin, Wnt3a, and Wnt5a) were evaluated using western blotting, revealing that the expression of these three proteins was significantly increased when HLY78 was administered immediately after ${ }^{12} \mathrm{C}^{6+}$ radiation. In our previous study, nuclear $\beta$-catenin concentrations, after combined treatments with XAV939 (Wnt signaling pathway inhibitor) and ${ }^{12} \mathrm{C}^{6+}$ radiation, were significantly lower than irradiation alone treatments (31). Immunofluorescence staining revealed that $\beta$-catenin expression in the nucleus was notably increased when HLY78 was administrated after ${ }^{12} \mathrm{C}^{6+}$ radiation, in comparison to radiation alone cells. These data when combined with western blotting results, indicated that HLY78 altered the nuclear localization of $\beta$-catenin, leading to increased canonical Wnt signaling, and the promotion of cell survival. Collectively, these results revealed that HLY78 promoted the progression of cervical cancer via activation of the $\mathrm{Wnt} / \beta$-catenin signaling pathway. Notably, the non-canonical Wnt pathway appears to be activated, however, the mechanism remains poorly understood.

Evidence has revealed that ${ }^{12} \mathrm{C}^{6+}$ particles produce high levels of clustered DNA damage, including DSBs, which are implicated in cell lethality after irradiation $(46,47)$. Since $\gamma-\mathrm{H} 2 \mathrm{AX}$ has been demonstrated to form nuclear foci upon $\mathrm{DSB}$, and previous studies have revealed that after irradiation with ${ }^{12} \mathrm{C}^{6+}$, a number of $\gamma$-H2AX foci increased at $4 \mathrm{~h}(48,49)$, in the present study, $\gamma-\mathrm{H} 2 \mathrm{AX}$ expression was assessed $4 \mathrm{~h}$ post-irradiation, and further detected by immunofluorescence. The results indicated that after irradiation with ${ }^{12} \mathrm{C}^{6+}$, HeLa cells exhibited an increased number of $\gamma-\mathrm{H} 2 \mathrm{AX}$ foci. However, Wnt signaling activation by HLY78 alleviated this effect. This result could support our theory that the Wnt/ $\beta$-catenin pathway activator HLY78 could reduce the DNA damage to protect HeLa cells from radiation-induced damage. Research has revealed that prolonged cell cycle arrest occurs after exposure to high-LET ionizing radiation (47). In addition, it is reported that aberrant activation of Wnt signaling by HLY78 could significantly alleviate the overexpression of ORP8-induced mitochondrial apoptotic events in gastric cancer cells (38). In the present study, HeLa cells irradiated with ${ }^{12} \mathrm{C}^{6+}$ exhibited increased cell apoptosis, and $\mathrm{G} 2 / \mathrm{M}$ phase arrest at $24 \mathrm{~h}$, in comparison with control cells. The addition of HLY78 significantly intensified the effects induced by ${ }^{12} \mathrm{C}^{6+}$ radiation alone. p53 activation and the mitochondrial apoptotic pathway contribute to IR-induced cellular damage (34). Equally, Wnt signaling may prevent apoptosis by antagonizing p53 and mitochondrial apoptosis pathways. The present findings revealed that the addition of HLY78 after ${ }^{12} \mathrm{C}^{6+}$ radiation, suppressed the increase of $\mathrm{p} 53$ and Bax expression, and the decrease of Bcl-2 expression induced by radiation alone. This was in agreement with our previous study, which indicated that HLY78 had a protective role against ${ }^{12} \mathrm{C}^{6+}$ radiation-induced cell apoptosis (34). Thus, HLY78, as a specific Wnt synergistic activator, exhibited protective roles against IR-induced cytotoxicity. Overall, the $\mathrm{Wnt} / \beta$ signaling pathway may be a promising molecular target for the treatment of cervical cancer.

In conclusion, the association between the canonical Wnt signaling pathway and cervical cancer was investigated. It was observed that HLY78 promoted the growth and proliferation of ${ }^{12} \mathrm{C}^{6+}$ radiated HeLa cells through the Wnt $/ \beta$-catenin pathway. These key observations revealed that the $\mathrm{Wnt} / \beta$-catenin signaling pathway played particularly important roles in ${ }^{12} \mathrm{C}^{6+}$ radiation-induced cytotoxicity, and may provide fundamental clinical applications relevant to the Wnt pathway in cancer therapeutics.

\section{Acknowledgements}

We express our thanks to the accelerator crew at the HIRFL, Institute of Modern Physics, Chinese Academy of Sciences (Lanzhou, China) and to all the institutions which provided financial support.

\section{Funding}

Financial support was provided by the National Key R\&D Program of China (2018YFE0205100), the National Natural Science Foundation of China (nos. 11675234, 11875061 and 31560254), the Science and Technology Plan Project of Chengguan, Lanzhou (2019RCCX0071), the Lanzhou Talent Innovation and Entrepreneurship Project (2019-RC-76) and the Key Program of the National Natural Science Foundation of China (U1632270).

\section{Availability of data and materials}

The datasets analysed during the current study are available from the corresponding author on reasonable request.

\section{Authors' contributions}

Experiments were conceived and designed by JS and HZ. Experiments were performed by JZ, LG and MG. Data were analyzed by FW, YX, CD, CS and JY. The study was written by JZ. All authors carefully reviewed, read and approved the manuscript and agree to be accountable for all aspects of the research in ensuring that the accuracy or integrity of any part of the work are appropriately investigated and resolved.

\section{Ethics approval and consent to participate}

Not applicable.

\section{Patient consent for publication}

Not applicable.

\section{Competing interests}

The authors declare that they have no competing interests. 


\section{References}

1. Cohen PA, Jhingran A, Oaknin A and Denny L: Cervical cancer Lancet 393: 169-182, 2019.

2. Sawaya GF, Smith-McCune K and Kuppermann M: Cervical cancer screening: More choices in 2019. JAMA 321: 2018-2019, 2019.

3. Denny L, de Sanjose S,Mutebi M,Anderson BO,Kim J,Jeronimo J, Herrero R, Yeates K, Ginsburg O and Sankaranarayanan R: Interventions to close the divide for women with breast and cervical cancer between low-income and middle-income countries and high-income countries. Lancet 389: 861-870, 2017.

4. Mohamad O, Sishc BJ, Saha J, Pompos A, Rahimi A, Story MD, Davis AJ and Kim DWN: Carbon ion radiotherapy: A review of clinical experiences and preclinical research, with an emphasis on DNA Damage/Repair. Cancers (Basel) 9: piiE66, 2017.

5. Hagiwara Y, Oike T, Niimi A, Yamauchi M, Sato H, Limsirichaikul S, Held KD, Nakano T and Shibata A: Clustered DNA double-strand break formation and the repair pathway following heavy-ion irradiation. J Radiat Res 60: 69-79, 2019

6. Hamada N, Imaoka T, Masunaga S, Ogata T, Okayasu R, Takahashi A, Kato TA, Kobayashi Y, Ohnishi T, Ono K, et al: Recent advances in the biology of heavy-ion cancer therapy. J Radiat Res 51: 365-383, 2010.

7. Loeffler JS and Durante M: Charged particle therapy-optimization, challenges and future directions. Nat Rev Clin Oncol 10 411-424, 2013

8. Onishi M, Okonogi N, Oike T, Yoshimoto Y, Sato H, Suzuki Y, Kamada T and Nakano T: High linear energy transfer carbon-ion irradiation increases the release of the immune mediator high mobility group box 1 from human cancer cells. J Radiat Res 59: 541-546, 2018.

9. Matsumoto Y, Furusawa Y, Uzawa A, Hirayama R, Koike S, Ando K, Tsuboi K and Sakurai H: Antimetastatic effects of carbon-ion beams on malignant melanomas. Radiat Res 190 412-423, 2018

10. Kamada T, Tsujii H, Blakely EA, Debus J, De Neve W, Durante M, Jäkel O, Mayer R, Orecchia R, Pötter R, et al: Carbon ion radiotherapy in Japan: An assessment of 20 years of clinical experience. Lancet Oncol 16: e93-e100, 2015.

11. Zhang P, Hu X, Liu B, Liu Z, Liu C, Cai J, Gao F, Cui J, Li B and Yang Y: Effects of ${ }^{12} \mathrm{C}^{6+}$ heavy ion radiation on dendritic cells function. Med Sci Monit 24: 1457-1463, 2018.

12. Sai S, Vares G, Kim EH, Karasawa K, Wang B, Nenoi M, Horimoto $\mathrm{Y}$ and Hayashi $\mathrm{M}$ : Carbon ion beam combined with cisplatin effectively disrupts triple negative breast cancer stem-like cells in vitro. Mol Cancer 14: 166, 2015.

13. Oike T, Niimi A, Okonogi N, Murata K, Matsumura A Noda SE, Kobayashi D, Iwanaga M, Tsuchida K, Kanai T, et al: Visualization of complex DNA double-strand breaks in a tumor treated with carbon ion radiotherapy. Sci Rep 6: 22275, 2016.

14. Ando $\mathrm{K}$ and Kase Y: Biological characteristics of carbon-ion therapy. Int J Radiat Biol 85: 715-728, 2009.

15. Lazar AA, Schulte R, Faddegon B, Blakely EA and Roach M III: Clinical trials involving carbon-ion radiation therapy and the path forward. Cancer 124: 4467-4476, 2018.

16. Fossati P, Matsufuji N, Kamada T and Karger CP: Radiobiological issues in prospective carbon ion therapy trials. Med Phys 45: e1096-e1110, 2018

17. Wakatsuki M, Kato S, Ohno T, Karasawa K, Kiyohara H, Tamaki T, Ando K, Tsujii H, Nakano T, Kamada T, et al: Clinical outcomes of carbon ion radiotherapy for locally advanced adenocarcinoma of the uterine cervix in phase $1 / 2$ clinical trial (protocol 9704). Cancer 120: 1663-1669, 2014.

18. Danieau G, Morice S, Redini F, Verrecchia F and Royer BB: New insights about the $\mathrm{Wnt} / \beta$-catenin signaling pathway in primary bone tumors and their microenvironment: A promising target to develop therapeutic strategies? Int J Mol Sci 20: pii: E3751, 2019.

19. Hua F, Liu S, Zhu L, Ma N, Jiang S and Yang J: Highly expressed long non-coding RNA NNT-AS1 promotes cell proliferation and invasion through $\mathrm{Wnt} / \beta$-catenin signaling pathway in cervical cancer. Biomed Pharmacother 92: 1128-1134, 2017.

20. Loh KM, van Amerongen R and Nusse R: Generating cellular diversity and spatial form: Wnt signaling and the evolution of multicellular animals. Dev Cell 38: 643-655, 2016.

21. Wang B, Tian T, Kalland KH, Ke X and Qu Y: Targeting Wnt/ beta-catenin signaling for cancer immunotherapy. Trends Pharmacol Sci 39: 648-658, 2018.
22. Oren $\mathrm{O}$ and Smith BD: Eliminating cancer stem cells by targeting embryonic signaling pathways. Stem Cell Rev 13: 17-23, 2017.

23. vallée A, Lecarpentier Y and Vallée JN: Curcumin: A therapeutic strategy in cancers by inhibiting the canonical WNT/ $\beta$-catenin pathway. J Exp Clin Cancer Res 38: 323, 2019.

24. Bahrami A, Hasanzadeh M, ShahidSales S, Yousefi Z, Kadkhodayan S, Farazestanian M, Joudi Mashhad M, Gharib M, Mahdi Hassanian S and Avan A: Clinical significance and prognosis value of wnt signaling pathway in cervical cancer. J Cell Biochem 118: 3028-3033, 2017

25. Ramachandran I, Ganapathy V, Gillies E, Fonseca I, Sureban SM, Houchen CW, Reis A and Queimado L: Wnt inhibitory factor 1 suppresses cancer stemness and induces cellular senescence. Cell Death Dis 5: e1246, 2014.

26. Ghosh N, Hossain U, Mandal A and Sil PC: The Wnt signaling pathway: A potential therapeutic target against cancer. Ann N Y Acad Sci 1443: 54-74, 2019.

27. Ma S, Deng X, Yang Y, Zhang Q, Zhou T and Liu Z: The lncRNA LINC00675 regulates cell proliferation, migration, and invasion by affecting Wnt $/ \beta$-catenin signaling in cervical cancer. Biomed Pharmacother 108: 1686-1693, 2018.

28. Yang G, Shen T, Yi X, Zhang Z, Tang C, Wang L, Zhou Y and Zhou W: Crosstalk between long non-coding RNAs and Wnt/ beta-catenin signalling in cancer. J Cell Mol Med 22: 2062-2070, 2018.

29. Lan K, Zhao Y, Fan Y, Ma B, Yang S, Liu Q, Linghu H and Wang H: Sulfiredoxin may promote cervical cancer metastasis via Wnt/ $\beta$-catenin signaling pathway. Int J Mol Sci 18: pii: E917, 2017.

30. Kwan HT, Chan DW, Cai PC, Mak CS, Yung MM, Leung TH, Wong OG, Cheung AN and Ngan HY: AMPK activators suppress cervical cancer cell growth through inhibition of DVL3 mediated Wnt/ßand -catenin signaling activity. PLoS One 8: e53597, 2013.

31. Zhang J, Si J, Gan M, Yan J, Chen Y, Wang F, Xie T, Wang Y and Zhang H: Inhibition of Wnt signalling pathway by XAV939 enhances radiosensitivity in human cervical cancer HeLa cells. Artif Cells Nanomed Biotechnol 48: 479-487, 2020.

32. Chen D, Zhang H, Jing C, He X, Yang B, Cai J, Zhou Y, Song X, Li L and Hao X: Efficient synthesis of new phenanthridine Wnt/ $\beta$-catenin signaling pathway agonists. Eur J Med Chem 157: 1491-1499, 2018

33. Chen DZ, Yang BJ, He XL, Fan SR, Cai JY, Jing CX, Zhang H, Zhang Y, Li L and Hao XJ: Design, synthesis and structure-activity relationship optimization of phenanthridine derivatives as new Wnt $/ \beta$-catenin signalling pathway agonists. Bioorg Chem 84: 285-294, 2019.

34. Si J, Zhou R, Zhao B, Xie Y, Gan L, Zhang J, Wang Y, Zhou X, Ren X and Zhang H: Effects of ionizing radiation and HLY78 on the zebrafish embryonic developmental toxicity. Toxicology 411: 143-153, 2019.

35. Mao A,Zhao Q, Zhou X, Sun C, Si J, Zhou R, Gan L and Zhang H: MicroRNA-449a enhances radiosensitivity by downregulation of c-Myc in prostate cancer cells. Sci Rep 6: 27346, 2016.

36. Ayala-Calvillo E, Mojica-Vazquez LH, Garcia-Carranca A and Gonzalez-Maya L: Wnt/ $\beta$-catenin pathway activation and silencing of the APC gene in HPVpositive human cervical cancerderived cells. Mol Med Rep 17: 200-208, 2018.

37. Venkatadri R, Iyer AKV, Kaushik V and Azad N: A novel resveratrol-salinomycin combination sensitizes ER-positive breast cancer cells to apoptosis. Pharmacol Rep 69: 788-797, 2017.

38. Guo X, Zhang L, Fan Y, Zhang D, Qin L, Dong S and Li G: Oxysterol-binding protein-related protein 8 inhibits gastric cancer growth through induction of er stress, inhibition of Wnt signaling, and activation of apoptosis. Oncol Res 25: 799-808, 2017.

39. Zhang $\mathrm{J}$ and Gao Y: CCAT-1 promotes proliferation and inhibits apoptosis of cervical cancer cells via the Wnt signaling pathway. Oncotarget 8: 68059-68070, 2017.

40. Zhang Y, Liu B, Zhao Q, Hou T and Huang X: Nuclear localizaiton of beta-catenin is associated with poor survival and chemo-/radioresistance in human cervical squamous cell cancer. Int J Clin Exp Pathol 7: 3908-3917, 2014.

41. Hai B, Yang Z, Shangguan L, Zhao Y, Boyer A and Liu F: Concurrent transient activation of $\mathrm{Wnt} / \beta$-catenin pathway prevents radiation damage to salivary glands. Int J Radiat Oncol Biol Phys 83: e109-116, 2012.

42. Saha S, Aranda E, Hayakawa Y, Bhanja P, Atay S, Brodin NP, Li J, Asfaha S, Liu L, Tailor Y, et al: Macrophage-derived extracellular vesicle-packaged WNTs rescue intestinal stem cells and enhance survival after radiation injury. Nat Commun 7: 13096, 2016. 
43. Wang S, Yin J, Chen D, Nie F, Song X, Fei C, Miao H, Jing C, Ma W, Wang L, et al: Small-molecule modulation of Wnt signaling via modulating the Axin-LRP5/6 interaction. Nat Chem Biol 9: 579-585, 2013.

44. Xiao CH, Yu HZ, Guo CY, Wu ZM, Cao HY, Li WB and Yuan JF: Long non-coding RNA TUG1 promotes the proliferation of colorectal cancer cells through regulating Wnt/ $\beta$-catenin pathway. Oncol Lett 16: 5317-5324, 2018.

45. Pereira-Suárez AL, Meraz MA, Lizano M, Estrada-Chávez C, Hernández F, Olivera P, Pérez E, Padilla P, Yaniv M, Thierry F and García-Carrancá A: Frequent alterations of the $\beta$-catenin protein in cancer of the uterine cervix. Tumour Biol 23: 45-53, 2002.

46. Sunada S, Hirakawa H, Fujimori A, Uesaka M and Okayasu R: Oxygen enhancement ratio in radiation-induced initial dsbs by an optimized flow cytometry-based $\Gamma-\mathrm{H} 2 \mathrm{AX}$ analysis in A549 human cancer cells. Radiat Res 188: 591-594, 2017.
47. Takahashi A, Yamakawa N, Kirita T, Omori K, Ishioka N, Furusawa Y, Mori E, Ohnishi K and Ohnishi T: DNA damage recognition proteins localize along heavy ion induced tracks in the cell nucleus. J Radiat Res 49: 645-652, 2008.

48. Yan J, Xie Y, Zhang Q, Gan L, Wang F, Li H, Si J and Zhang H: Dynamic recognition and repair of DNA complex damage. J Cell Physiol 234: 13014-13020, 2019.

49. Liu X, Li P, Hirayama R, Niu Y, Liu X, Chen W, Jin X, Zhang P, Ye F, Zhao T, et al: Genistein sensitizes glioblastoma cells to carbon ions via inhibiting DNA-PKcs phosphorylation and subsequently repressing NHEJ and delaying HR repair pathways. Radiother Oncol 129: 84-94, 2018. 